\title{
Evaluation of serum lipoprotein (a) in young patients with myocardial infarction
}

Context: Indians are prone as a community to coronary artery disease (CAD) at a much younger age. CAD is affecting Indians 5-10 years earlier than other communities. Lipoprotein (a) (Lp (a)) is now recognized as an independent risk factor for CAD. It is a genetic risk factor. Aim: We evaluate the $L p(a)$ in young patients with myocardial infarction (MI). Settings and design: Study population consisted of 50 patients having $\mathrm{MI}$ and 50 control groups. Subjects and Methods: Fasting samples were collected from patients and were analyzed for Lp (a), lipid profile, and blood sugar on fully automated analyzer. Statistical analysis used: Statistical analysis is carried out by using Student's $t$-test. Results: The difference in total cholesterol $(P=0.8192)$, high density lipoprotein-cholesterol (HDL-C) $(P=0.11)$, low density lipoprotein-cholesterol (LDL-C) $(P=0.8143)$, triglyceride $(P=0.1177)$ levels, and total cholesterol/HDLcholesterol ratio $(P=0.2129)$ were observed between the case and control groups in this study was not statistically significant. The difference in the $L p$ (a) levels between the case and control groups was highly significant $(P$-value $=0.0001)$. Conclusions: This study demonstrated that in young patients with $\mathrm{MI}$ there was a male predominance. Lp (a) level is an important and independent risk factor for CAD. Serum Lp (a) level is not dependent on serum total cholesterol level.

Key words: Coronary artery disease, lipid profile, lipoprotein (a)

\section{Chandrakant Pragjibhai Kamariya, Jignesh H. Gorasia, Uday Vachhani, Mukesh Gohel}

Department of Biochemistry, Pandit Deendayal Upadhyay Medical College, Rajkot, Gujarat, India

Address for the Correspondence: Dr. Chandrakant Kamariya, Department of Biochemistry, $2^{\text {nd }}$ floor, Pandit Deendayal Upadhyay Medical College, Jamnagar Road, Rajkot - 360001 , Gujarat, India.

E-mail: drkamariya@gmail.com

\begin{tabular}{|l|}
\hline Access this article online \\
\hline Website: www.ijmedph.org \\
\hline DOI: 10.4103/2230-8598.127169 \\
\hline Quick response code: \\
\hline
\end{tabular}

\section{INTRODUCTION}

Developing countries, especially like India are on the verge of twin epidemics of communicable and noncommunicable diseases namely hypertension and coronary artery disease (CAD). The prevalence of CAD is high amongst Indians; 2.2 to five times for myocardial infarction (MI) and 1.5 to three times for CAD mortality. MI also occurs at a younger age in Indians (50.2 versus 55.5 years in whites). ${ }^{[1]}$

Age specific death rates (30-39) for MI in Indians were almost 10 times the rate observed for the white population. Autopsies also revealed more severe and extensive atherosclerosis and larger infarct size and increased frequency of triple vessel disease among Indians. ${ }^{[2]}$

In CAD, first reported from Singapore in 1959 reveal that people hailing from Indian subcontinent had a higher probability of dying due to CAD. The overall age standardized mortality ratio of CAD in Asian males compared to whites was 37.3\% higher in age group of 20-29 years, compared to 36\% higher at all ages in the UK. Asian Indians belonging to different geographical culture and religious groups have the same high mortality. Further, the prevalence of CAD is three-fold higher in south India in comparison to north India.

An important cluster of metabolic risk factors seems to be responsible for the occurrence of extensive and early CAD in Indians. These include the greater occurrence of glucose intolerance, hyperinsulinemia, hypertriglyceridemia, low high density lipoprotein-cholesterol (HDL-C) level, abnormal type of obesity, and novel risk factor like high serum lipoprotein (a) ( $\operatorname{Lp}(\mathrm{a})$ ).

Lp (a) constitutes an important inherited risk factor for atherosclerosis and is also regarded as biological marker for familial CAD. Lp (a) is homologous with the fibrin binding domain of plasminogen, a plasma protein that dissolves blood clots when activated. Lp (a) levels are also reduced by treatment with $\mathrm{N}$-acetyl cysteine. Nicotinic acid and neomycin also decrease levels of Lp (a) and are used for therapeutic purpose. ${ }^{[3]}$ 
This study was designed to explore the role of Lp (a) levels in young patients with MI. Young patients in the study were defined as patients with age $\leq 40$ years.

\section{SUBJECTS AND METHODS}

This case control study was carried out during the period of June 2008-January 2009 after prior approval from local ethical committee. Informed consent was taken from patients. Study population consisted of 50 patients having acute $\mathrm{MI}$ and diagnosed by clinical sign and symptoms, 12 lead electrocardiogram (ECG) and biochemical markers like creatinine kinase-MB (CK-MB) isoenzyme. Control group included 50 young individuals without ischemic heart disease.

Exclusion criteria include patient with uncontrolled diabetes mellitus, nephrotic syndrome, and treatment with any of lipid lowering agents.

Five milliliter of blood was collected in a plain bulb for estimation of Lp (a) and lipid profile. Two milliliter of blood was collected in a fluoride bulb for blood sugar estimation. Prior to sample collection, $10-12 \mathrm{~h}$ of fasting is required. Serum is preferred. Blood should be centrifuged within $30 \mathrm{~min}$. Investigations like fasting blood sugar (FBS), postprandial $2 \mathrm{~h}$ blood sugar $\left(\mathrm{PP}_{2} \mathrm{BS}\right)$, blood urea, serum creatinine, serum CK-MB, lipid profile, and serum Lp (a) were carried out in all patients and controls using commercially available kits on fully auto analyzer (Miura) machine. Serum Lp (a) was estimated by turbidimetric end point method. Comparison was carried out by using student's $t$-test. The differences were considered as significant if $P$-value was $<0.05$.

\section{RESULTS}

Out of 50 patients with MI, 12 were females and rests of all were males (male to female ratio was 3.2). Thus, there was a male preponderance.

The difference in total cholesterol levels between the case and control group was not significant $(P$-value $=0.8192)$. The difference in levels of HDL-C between the case and control groups was not statistically significant $(P$-value $=0.11)$. The difference in low density lipoproteincholesterol (LDL-C) levels observed between the case and control groups in this study was not statistically significant $(P$-value $=0.8143)$. The difference in the serum triglyceride levels between the case and control groups was not significant $(P$-value $=0.1177)$. The difference in the total cholesterol/HDL-C ratio between the case and control groups was not significant with the $P$-value of 0.2129 . The Lp (a) levels in case patients with serum total cholesterol $<200 \mathrm{mg} \%$ was statistically significantly $(P$-value $=0.001)$ higher in compare to controls. The difference in the Lp (a) levels between the case and control groups was highly significant $(P$-value $=0.0001)$ suggesting Lp $(a)$ as an important predictor of coronary heart disease [Tables 1-3].

\section{DISCUSSION}

Lp (a) has many properties in common with LDL-C, but contains a unique protein, Apo (a), which is structurally different

\begin{tabular}{|c|c|c|c|}
\hline \multirow[t]{2}{*}{ Parameters } & \multicolumn{2}{|c|}{ Cases $(n=50)$ Control $(n=50)$} & \multirow{2}{*}{$\begin{array}{c}\text { Statistical } \\
\text { significance } \\
(P \text {-value })\end{array}$} \\
\hline & Mean \pm SD & Mean \pm SD & \\
\hline $\begin{array}{l}\text { Total } \\
\text { cholesterol (mg\%) }\end{array}$ & $186.98 \pm 13.44$ & $184.44 \pm 11.1$ & 0.81 \\
\hline HDL-C (mg\%) & $42.52 \pm 3.10$ & $45.6 \pm 3.46$ & 0.11 \\
\hline LDL-C (mg\%) & $110.42 \pm 15.18$ & $104.77 \pm 13.15$ & 0.81 \\
\hline Triglyceride (mg\%) & $177.2 \pm 16.50$ & $170.32 \pm 15.42$ & 0.11 \\
\hline $\begin{array}{l}\text { Total cholesterol/ } \\
\text { HDL-C ratio }\end{array}$ & $4.18 \pm 0.42$ & $4.07 \pm 0.43$ & 0.21 \\
\hline $\begin{array}{l}\text { Lipoprotein } \\
\text { (a) (mg\%) }\end{array}$ & $44.04 \pm 8.52$ & $19.74 \pm 5.69$ & 0.0001 \\
\hline
\end{tabular}

\begin{tabular}{|c|c|c|}
\hline & $\begin{array}{c}\text { Serum total cholesterol } \\
<200 \mathrm{mg} \%\end{array}$ & Serum Lp (a) \\
\hline No. of Patients & 44 & 44 \\
\hline Mean $\pm S D$ & $182.54 \pm 10.49$ & $45.88 \pm 5.83$ \\
\hline
\end{tabular}

\begin{tabular}{|c|c|c|}
\hline & Cases & Controls \\
\hline Males & 38 & 32 \\
\hline Females & 12 & 18 \\
\hline
\end{tabular}

from other apolipoproteins. Apo (a) influences to major extent metabolic and physiochemical properties of $\mathrm{Lp}(\mathrm{a}) .^{[4-7]}$ There is an inverse relationship between Apo (a) size and Lp (a) levels. ${ }^{[8-10]}$ Lp (a) promotes atherosclerosis by various mechanisms. ${ }^{[1]}$

(a) The very low density lipoprotein (VLDL) receptors found on the macrophages present in atherosclerotic lesions can bind to and mediate the catabolism of Lp (a) by endocytosis, leading to its degradation within lysosomes. This would lead to a cellular accumulation of lipids within macrophages. Supporting this hypothesis is the observation that Lp (a) is ubiquitous in human coronary atheroma, co-localizes with plaque macrophages, and is detected in large amount in tissue from culprit lesions in patients with unstable compared to stable CAD. (b) Binding to endothelium and components of the extra cellular matrix, leading to endothelial dysfunction due to selective impairment of vasodilators capacity of receptor mediated endothelial stimuli.

(c) Enhancement of expression of intracellular adhesion molecule 1, resulting in the recruitment of monocytes to the vessel wall and binding to macrophages. This can promote foam cell formation and the localization of Lp (a) in atherosclerotic plaque.

(d) Prothrombotic mechanism: Given the extensive sequence homology between Apo (a) and plasminogen, it has been suggested that much of the atherogenic potential of Lp (a) derives from 
interference in normal pathways of thrombolysis, to predispose patients to acute thrombotic complications. ${ }^{[12]}$

These all data shows that only Lp (a) is found significantly $(99.9 \%)$ higher in compare to controls in patients of MI, while serum total cholesterol, serum HDL-cholesterol, serum LDL-cholesterol, and serum triglyceride level does not have any significant difference. It means Lp (a) has played role as independent risk factor for MI. The patient who did not have high levels of serum total cholesterol $(<200 \mathrm{mg} \%$ ), the higher levels of serum Lp (a) triggered the CAD. Thus, Lp (a) level is not dependent on serum total cholesterol level. This again means that Lp (a) can be an independent risk factor for MI. Sandkamp and Funke reported the same findings. ${ }^{[13]}$

$\mathrm{Lp}$ (a) is considered to be 10 times more atherogenic than LDL-C. ${ }^{[14]}$ Relative risk of CAD is increased three-fold in males if $\mathrm{Lp}$ (a) levels are above $30 \mathrm{mg} / \mathrm{dl}^{\left[{ }^{[15,16]}\right.}$ Adverse effects are enhanced by high LDL-C and low values of HDL-C.

\section{CONCLUSION}

In young patients with MI there was a male predominance. Hyper Lp (a) level is an important and independent predictor of MI and independent risk factor for CAD. Serum Lp (a) level is not dependent on serum total cholesterol level. Selective screening for primary and secondary prevention should be considered for high-risk patients.

\section{REFERENCES}

1. Huges LO, Raval U, Raftery EB. First myocardial infarction in Asian and white men. BMJ 1989;298:1345-50.

2. Lowry PJ, Glover DJ, Mace PJ, Litter WA. Coronary heart disease in Asians in Birmingham. Br Heart Jr 1984;52:610-30.

3. Wallidius G, Jungner I. Apolipoprotein B and apolipoprotein A-I: Risk indicators of coronary heart disease and targets for lipid-modifying therapy. J Intern Med 2004;255:188-205.
4. Hobbs HH, White AL. Lipoprotein (a): Intrigues and insights. Curr Opin Lipidol 1999;10:225-36.

5. Berglund L. Diet and drug therapy for lipoprotein (a). Curr Opin Lipidol 1995;6:48-56.

6. Edelstein C, Italia JA, Klezovitch O, Scanu AM. Functional and metabolic differences between elastase-generated fragments of human lipoprotein (a) and apolipoprotein (a). J Lipid Res 1996;37:1786-801.

7. Galvano $F$, Malaguarnera $M$, Vacante $M$, Motta $M$, Russo $C$, Malaguarnera G, et al. The physiopathology of lipoprotein (a). Front Biosci (Schol Ed) 2010;2:866-75.

8. Gavish D, Azrolan N, Breslow JL. Plasma Ip (a) concentration is inversely correlated with the ratio of Kringle IV/Kringle $\mathrm{V}$ encoding domains in the apo(a) gene. J Clin Invest 1989;84:2021-7.

9. Kraft HG, Kochl S, Menzel HJ, Sandholzer C, Utermann G. The apolipoprotein (a) gene: A transcribed hypervariable locus controlling plasma lipoprotein (a) concentration. Hum Genet 1992;90:220-30.

10. Rosby O, Berg K. LPA gene: Interaction between the apolipoprotein (a) size ('kringle IV' repeat) polymorphism and a pentanucleotide repeat polymorphism influences Lp (a) lipoprotein level. J Intern Med 2000;247:139-52.

11. Morishita R, Ishii J, Kusumi Y, Yamada S, Komai N, Ohishi M, et al. Association of serum oxidized lipoprotein (a) concentration with coronary artery disease: Potential role of oxidized lipoprotein (a) in the vascular wall. J Atheroscler Thromb 2009;16:410-8.

12. Xue S, Madison EL, Miles LA. The Kringle V-protease domain is a fibrinogen binding region within Apo (a). Thromb Haemost 2001;86:1229-37.

13. Sandkamp M, Funke H, Schulte H, Köhler E, Assmann G. Lipoprotein(a) is an independent risk factor for myocardial infarction at a young age. Clin Chem 1990;36:20-3.

14. Lawn RM. Lipoprotein (a) in heart disease. Sci Am 1992;266:54-60.

15. Maher VM, Brown BG, Marcovina SM, Hillger LA, Zhao XQ, Albers JJ. Effect of lowering LDL cholesterol on cardiovascular risk of lipoprotein (a). JAMA 1995;274:1771-4.

16. Armstrong VW, Cremer P, Eberle E, Manke A, Schulze F, Wieland $\mathrm{H}$, et al. The association between serum $L p(a)$ concentrations and angiographically accessed coronary atherosclerosis. Dependence on serum LDL levels. Atherosclerosis 1986;62:249-57.

How to cite this article: Kamariya CP, Gorasia JH, Vachhani U, Gohel M. Evaluation of serum lipoprotein (a) in young patients with myocardial infarction. Int J Med Public Health 2014;4:107-9.

Source of Support: Nil, Conflict of Interest: None declared. 